\title{
Correction to: PAKs supplement improves immune status and body composition but not muscle strength in resistance trained individuals
}

Frederico Gerlinger-Romero ${ }^{1,2}$, Fabio S. Lira ${ }^{2,3}$, Fernando A. Marques², Paulo C. Muzy², Rodolfo A. N. Peres² and Érico C. Caperuto $2,4^{*}$

\section{Correction}

The original article [1] contains an error whereby the author, Frederico Gerlinger-Romero's name is displayed incorrectly; the correct spelling is instead displayed in this Correction article.

\section{Author details}

${ }^{1}$ Department of Physiology, Institute of Biomedical Sciences, University of São Paulo, São Paulo, Brazil. ${ }^{2}$ Institute of Science in Nutrition and Performance, São Paulo, Brazil. ${ }^{3}$ Department of Physiology, Division of Nutrition Physiology, Federal University of São Paulo, São Paulo, Brazil. ${ }^{4}$ Department of Biodynamic, Mackenzie Presbiterian University, São Paulo, Brazil.

Received: 14 November 2018 Accepted: 14 November 2018

Published online: 27 November 2018

\section{Reference}

1. Gerlinger-Romero F, et al. PAKs supplement improves immune status and body composition but not muscle strength in resistance trained individuals. J Int Soc Sports Nutr. 2010;7:36 https://doi.org/10.1186/1550-2783-7-36.

\footnotetext{
* Correspondence: ecaperuto@yahoo.com

${ }^{2}$ Institute of Science in Nutrition and Performance, São Paulo, Brazil

${ }^{4}$ Department of Biodynamic, Mackenzie Presbiterian University, São Paulo,

Brazil

Full list of author information is available at the end of the article
} 